\title{
BMJ Open Protective factors for child development at age 2 in the presence of poor maternal mental health: results from the All Our Babies (AOB) pregnancy cohort
}

\author{
Sheila W McDonald, ${ }^{1}$ Heather L Kehler, ${ }^{1}$ Suzanne C Tough ${ }^{2}$
}

To cite: McDonald SW, Kehler HL, Tough SC. Protective factors for child development at age 2 in the presence of poor maternal mental health: results from the All Our Babies (AOB) pregnancy cohort. BMJ Open 2016;6:e012096.

doi:10.1136/bmjopen-2016012096

- Prepublication history and additional material is available. To view please visit the journal (http://dx.doi.org/ 10.1136/bmjopen-2016012096).

Received 30 March 2016 Revised 8 October 2016 Accepted 13 October 2016

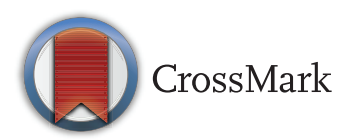

${ }^{1}$ Department of Pediatrics, Cumming School of Medicine, University of Calgary, Calgary, Alberta, Canada

${ }^{2}$ Departments of Pediatrics and Community Health Sciences, Cumming School of Medicine, University of Calgary, Calgary, Alberta, Canada

Correspondence to Dr Sheila W McDonald; SheilaW.McDonald@ albertahealthservices.ca

\section{ABSTRACT}

Objective: To identify the combination of factors most protective of developmental delay at age 2 among children exposed to poor maternal mental health.

Design: Observational cohort study.

Setting: Pregnant women were recruited from primary healthcare offices, the public health laboratory service and community posters in Calgary, Alberta, Canada.

Participants: 1596 mother-child dyads who participated in the All Our Babies study and who completed a follow-up questionnaire when their child was 2 years old. Among participants who completed the 2-year questionnaire and had complete mental health data $(n=1146), 305$ women $(27 \%)$ were classified as high maternal mental health risk.

Primary measures: Child development at age 2 was described and a resilience analysis was performed among a subgroup of families at maternal mental health risk. The primary outcome was child development problems. Protective factors were identified among families at risk, defined as maternal mental health risk, a composite measure created from participants' responses to mental health life course questions and standardised mental health measures.

Results: At age 2,18\% of children were classified as having development problems, $15 \%$ with behavioural problems and $13 \%$ with delayed socialemotional competencies. Among children living in a family with maternal mental health risk, protective factors against development problems included higher social support, higher optimism, more relationship happiness, less difficulty balancing work and family responsibilities, limiting the child's screen time to $<1$ hour per day and the child being able to fall asleep in $<30$ min and sleeping through the night by age 2 .

Conclusions: Among families where the mother has poor mental health, public health and early intervention strategies that support interpersonal relationships, social support, optimism, work-life balance, limiting children's screen time and establishing good sleep habits in the child's first 2 years show promise to positively influence early child development.

\section{Strengths and limitations of this study}

- A community-based multimethods recruitment strategy was implemented to obtain a socioeconomically and ethnically diverse sample of women representative of the parenting population in Calgary, Canada.

- Comprehensive questionnaire and medical record data were collected spanning pregnancy, birth, early postpartum and early childhood providing a unique opportunity to consider multiple protective factors for child development in the context of poor maternal mental health.

- The primary outcome, child development problems, was based on parent report on standardised measures, not clinical diagnoses, and therefore the possibility for misclassification must be considered when interpreting the findings of this analysis.

- The sociodemographics of participants, including the percentage with higher household incomes, secondary education and committed relationships, while representative of the pregnant and parenting population in an urban centre in Canada, may be higher than that observed in other populations, and therefore the generalisability of our findings to other populations should be interpreted with caution.

- Attrition of the longitudinal sample may further limit generalisability.

\section{INTRODUCTION}

A developmental delay is described as not reaching a developmental milestone by the expected age. ${ }^{1}$ Recent studies in Canada and the USA suggest that developmental delays affect an estimated $11-21 \%$ of preschool aged children. ${ }^{2}{ }^{3}$ By kindergarten, at $\sim$ age 5 years, current population-level data in Canada suggest that the percentage of children with a developmental vulnerability is $25-30 \%{ }^{4}$

Early developmental delays are associated with future negative outcomes including 
lower school readiness and poor school performance. ${ }^{56}$ Social-emotional delays and behavioural problems at preschool age are associated with later negative outcomes at school age including ongoing behaviour problems, ${ }^{7}{ }^{8}$ psychiatric disorders ${ }^{8}$ and negative social outcomes including less social acceptance ${ }^{9}$ and a limited ability to form and maintain quality friendships. ${ }^{10}$

Maternal depression is an established risk factor for child developmental delay. ${ }^{11}$ In a recent review, maternal mental health problems in pregnancy and/or the postpartum period were found to increase the likelihood that school age children experienced suboptimal global, behavioural, cognitive and socioemotional development. ${ }^{11}$ Poor maternal mental health is common, with recent studies reporting that $25 \%$ of women are affected at some time between conception and 1 year postpartum. ${ }^{12}$ Therefore, children whose mothers experience poor mental health represent a significant high-risk group for early developmental delay. Despite this adversity, some children do not experience any delay in development and seem to have a resilience that suggests there may be factors that can play a protective role. A better understanding of protective factors has important implications for public health and early intervention strategies to optimise early child development.

Early child development is a dynamic process occurring over time and influenced by genetics, in utero development and prenatal and postnatal environmental factors. ${ }^{13}$ Consequently, a comprehensive investigation of factors across pregnancy, birth, early postpartum and early childhood would provide the strongest evidence to inform early identification and intervention. The All Our Babies (AOB) study, with its prospective data collection strategy including five questionnaires from mid-pregnancy to 2 years postpartum, provides a unique opportunity to consider multiple protective factors for child development in the context of poor maternal mental health.

The objective of the present study was to describe child development at age 2 and to identify factors most protective of developmental and behavioural problems among a subgroup of children exposed to poor maternal mental health.

\section{METHODS}

The AOB study is a prospective community-based pregnancy cohort of $\sim 3000$ women and their children. ${ }^{4}$ Women were recruited during pregnancy and asked to complete three questionnaires and to consent to provide the research team with access to their obstetrical and birth records. Those who consented to be contacted for future research were asked to participate in subsequent follow-up questionnaires when their child was 1 and 2 years old.

\section{Participant recruitment}

The initial sample for the AOB cohort was obtained through a community-based recruitment strategy involving primary healthcare offices, community posters and the public health laboratory service (Calgary Laboratory Service). This multimethod strategy was designed to obtain a socioeconomically and ethnically diverse sample of women representative of the parenting population in an urban Canadian centre. Recruitment began in May 2008 and was completed in December 2010. Women were eligible to participate in the AOB study if they were $<24$ weeks and 6 days gestation at the time of enrolment, they were 18 years of age or older, they lived in the greater Calgary area and they were able to complete a written questionnaire in English. Women were excluded from the AOB study if they planned to move outside the greater Calgary area during their pregnancy. Detailed descriptions of the AOB study design and methods have previously been described. ${ }^{14}$

\section{Participant follow-up}

Eligible participants for each follow-up questionnaire were contacted and invited to participate over the telephone. At follow-up waves, only those participants who were deemed eligible according to their child's age were mailed questionnaires. Starting at the 1 year follow-up, the sample size decreased due to timing of questionnaire design and implementation, ethics approval, funding constraints and attrition. Women who agreed to participate were mailed a written questionnaire and a postage paid return envelope to return the completed questionnaire to the research team. Participants were contacted if questionnaire data were missing or clarification of responses was required. Participants who did not return the completed questionnaire were contacted by telephone and email to provide an opportunity for a repeat mail-out or to complete the questionnaire over the phone.

\section{Data collection}

The AOB questionnaires were developed with input from healthcare providers, epidemiologists and community programme experts. Standardised measures were included as part of the questionnaires when available.

\section{Main outcome: child development}

Two standardised instruments: (1) the Ages and Stages Questionnaire (ASQ ${ }^{15}$ and (2) the Brief Infant-Toddler Social and Emotional Assessment (BITSEA) ${ }^{16}{ }^{17}$ were used to measure the primary outcome of child development.

The ASQ measures five domains of development (communication, gross motor, fine motor, problem solving and personal-social).$^{15}$ The ASQ shows excellent indices of reliability and validity. ${ }^{18}$ In accordance with the author's scoring instructions, the risk category of each domain was defined as scoring $1 \mathrm{SD}$ below the mean of the ASQ normative data, which classifies children as scoring in at least the 'monitoring zone' and potentially the 'referral zone'. ${ }^{15}$ At 2 SDs below the mean, children are considered to be in the 'referral zone'. Given the low cell sizes for this latter category in our sample, we used the 1 SD cut-off. An overall 
composite measure of child development was defined as scoring 'at risk' in at least two of the five domains on the ASQ, which aligns with an overall proportion of delay as seen in the literature, ranging from $12 \%$ to $16 \%{ }^{19}{ }^{20}$

The BITSEA measures child behavioural problems (aggression, defiance, overactivity, negative emotionality, anxiety and withdrawal) and social-emotional competencies (empathy, prosocial behaviours and compliance). ${ }^{16} 17$ The two BITSEA subscales have been found to have satisfactory reliability and validity. ${ }^{16}$ Using the standardised scoring cut-offs from the published normative data, children were categorised with behavioural problems if they scored at or below the 25th centile of normative data and children were categorised with delayed social-emotional competencies if they scored at or below the 15 th centile of normative data. ${ }^{17}$

\section{Maternal mental health risk}

Previous research by our team and others has identified that the accumulation of adverse experiences confers the greatest risk to maternal mental health in the postpartum period. ${ }^{11}{ }^{21}$ Consequently, we incorporated a life course approach to the definition of maternal mental health risk defined as experiencing two or more of the following: a history of any abuse; a history of any mental health disorder; depression or anxiety during pregnancy; depression or anxiety at 4 months postpartum; or depression or anxiety at 1 year postpartum. Standardised measures included the Edinburgh Postnatal Depression Scale (EPDS), ${ }^{22}$ the Centre for Epidemiologic Studies Depression Scale (CES-D) ${ }^{23}$ and the Spielberger State Anxiety Inventory (SAI) ${ }^{24}$ This definition of maternal mental health risk has been used in previous studies examining protective factors for child development in the presence of elevated risk and resilience analyses. $^{2} 2125$

\section{Independent variables}

Among the subgroup of families with maternal mental health risk, protective factors examined included maternal sociodemographics, maternal social support, maternal optimism, maternal relationship happiness, maternal community resource use, birth outcomes, childcare arrangement, child sleep habits, child screen time, child physical activity level, child second language exposure, maternal working status and parenting outcomes. Standardised measures included the Medical Outcomes Study Social Support Survey (MOS-SSS), ${ }^{26}$ the Life-Orientation Test-Revised (LOT-R), ${ }^{27}$ the Parenting Morale Index (PMI ${ }^{28}$ and the National Longitudinal Survey of Children and Youth Social Support Scale (NLSCY-SSS). ${ }^{29}$ All potential protective factors for child development examined in this study are described in detail in online supplementary appendix A.

Participants provided informed consent at the time of recruitment and were provided with copies of the consent form for their records.

\section{Data analysis}

Stata (V.12.1) was used to conduct all statistical analyses. A complete case approach was used for all analyses. Descriptive statistics were used to describe participant characteristics and child development outcomes at age 2. Frequencies and percentages were calculated for categorical variables and means and SDs were calculated for continuous variables.

Among the subgroup of participants exposed to higher maternal mental health risk, an initial bivariate analysis was conducted to identify factors that were protective for each of the child development outcomes. Associations were assessed using Pearson's $\chi^{2}$ test or Fisher's exact test when cell counts were fewer than five. Risk factors identified at the bivariate level based on statistical significance at the $\mathrm{p}<0.10$ level were considered for inclusion in the subsequent multivariable models. For both child development outcomes, multivariable logistic regression modelling was conducted to identify the independent protective factors most strongly associated with child development in the presence of maternal mental health risk. A manual stepwise approach was used to build the models, with blocks of variables being added in sequential steps in the following order: (1) sociodemographic variables; (2) pregnancy and birth outcome variables; (3) postpartum variables (up to 1 year postpartum); and (4) parenting, childcare environment and community resource use variables (between 1 and 2 years postpartum). To best address the research objectives, these blocks were ordered conceptually in temporal order, and from least to most modifiable. Statistical significance was set at $\mathrm{p}<0.05$ for inclusion in the next step of the logistic regression modelling; variables in previous blocks that became non-significant on inclusion of a subsequent block of variables were removed at the final step. Model robustness was checked by adding in, one at a time, variables that were previously removed. Adjusted ORs with 95\% CIs were calculated. Final, parsimonious models are presented.

\section{RESULTS \\ Maternal participant characteristics}

Two-year follow-up questionnaire data were collected between October 2011 and October 2013. In total, 2106 women from the AOB study were eligible to participate in the 2-year follow-up, of whom 1596 completed and returned the questionnaire for a participation rate of $75.2 \%$.

The majority of participants were married or in a common law relationship (96\%), had postsecondary education (92\%), had household incomes above $\$ 60000$ (85\%), were born in Canada $(81 \%)$ and described their ethnicity as white or Caucasian (82\%). The average age of women at the 2-year follow-up was 33.9 years $(\mathrm{SD}=4.4)$. At 2 years postpartum, $13 \%$ of women had symptoms of depression and $15 \%$ of women had symptoms of anxiety (table 1 ). 
Table 1 Maternal participant characteristics

\begin{tabular}{|c|c|c|}
\hline Characteristic & $\mathbf{N}$ & $\mathbf{N}(\%)$ \\
\hline Marital status & 1596 & \\
\hline Married/common law & & $1536(96.24)$ \\
\hline $\begin{array}{l}\text { Single/separated/divorced/ } \\
\text { widowed }\end{array}$ & & $60(3.76)$ \\
\hline Maternal education & 1584 & \\
\hline High school or less & & $132(8.33)$ \\
\hline Some college, university or trade & & $1202(75.89)$ \\
\hline Postgraduate studies & & $250(15.78)$ \\
\hline $\begin{array}{l}\text { Total household income (before } \\
\text { taxes and deductions) }\end{array}$ & 1303 & \\
\hline$>\$ 60000$ & & $199(15.27)$ \\
\hline$\$ 60000-\$ 79999$ & & $210(16.12)$ \\
\hline$\$ 80000$ or more & & $894(68.61)$ \\
\hline Born in Canada & 1585 & \\
\hline Yes & & $1276(80.50)$ \\
\hline No & & 309 (19.50) \\
\hline Ethnicity & 1584 & \\
\hline White/Caucasian & & $1301(82.13)$ \\
\hline Other & & $283(17.87)$ \\
\hline Maternal age, mean (SD) & 1567 & $33.91(4.42)$ \\
\hline Depression (CES-D) & 1596 & \\
\hline No $(C E S-D<16)$ & & $1396(87.47)$ \\
\hline Yes (CES-D $\geq 16)$ & & $200(12.53)$ \\
\hline Anxiety (SAI) & 1576 & \\
\hline No $(\mathrm{SAI}<40)$ & & $1334(84.64)$ \\
\hline Yes $(S A I \geq 40)$ & & $242(15.36)$ \\
\hline $\begin{array}{l}\text { Data reported from most recent time po } \\
\text { CES-D, the Centre for Epidemiologic S } \\
\text { SAI, the Spielberger State Anxiety Inve }\end{array}$ & $\begin{array}{l}\text { available } \\
\text { ies Depr } \\
\text { ry. }\end{array}$ & ession Scale; \\
\hline
\end{tabular}

Comparison of sample characteristics among those who participated at baseline and those who remained at follow-up showed that continuing participants were more likely to have higher socioeconomic status (SES), to be older, to be in a stable relationship and to be born in Canada (unpublished results).

\section{Child development outcomes at 2 years}

At age 2, $14 \%$ of children were identified with a communication delay, $14 \%$ with a gross motor delay, $12 \%$ with a fine motor delay, $14 \%$ with a problem-solving delay and $16 \%$ with a personal-social delay, using the 1 SD cut-off (at least the 'monitoring zone'; table 2). At 2 years of age, $18 \%$ of children scored 'at risk' in two or more domains on the ASQ. Using the BITSEA, $13 \%$ of children had delayed social-emotional abilities and 15\% had behavioural problems at age 2 (table 2 ).

\section{Resilience analysis: protective factors that mitigate the} risk for developmental delay in the context of maternal mental health risk

Among participants who completed the 2-year questionnaire (and for whom complete mental health data were available $(n=1146)), 305$ women $(27 \%)$ were classified as high maternal mental health risk.
Table 2 Child development outcomes at age 2

\begin{tabular}{|c|c|c|}
\hline Child characteristics & $\mathbf{N}$ & $\mathbf{N}(\%)$ \\
\hline Communication development (ASQ) & 1403 & \\
\hline Not delayed & & 1205 (85.89) \\
\hline Delayed & & $198(14.11)$ \\
\hline Gross motor development (ASQ) & 1408 & \\
\hline Not delayed & & $1217(86.43)$ \\
\hline Delayed & & $191(13.57)$ \\
\hline Fine motor development (ASQ) & 1400 & \\
\hline Not delayed & & $1238(88.43)$ \\
\hline Delayed & & $162(11.57)$ \\
\hline Problem-solving development (ASQ) & 1401 & \\
\hline Not delayed & & $1203(85.87)$ \\
\hline Delayed & & $198(14.13)$ \\
\hline Personal social development (ASQ) & 1407 & \\
\hline Not delayed & & $1183(84.08)$ \\
\hline Delayed & & $224(15.92)$ \\
\hline Overall child development (ASQ) & 1383 & \\
\hline $0-1$ delayed domains & & 1139 (82.36) \\
\hline 2-5 delayed domains & & $244(17.64)$ \\
\hline $\begin{array}{l}\text { Social-emotional abilities } \\
\text { (eg, empathy, prosocial behaviours } \\
\text { and compliance; BITSEA) }\end{array}$ & 1579 & \\
\hline No problems & & 1369 (86.70) \\
\hline Possible deficit/delay range & & $210(13.30)$ \\
\hline $\begin{array}{l}\text { Behavioural problems } \\
\text { (eg, aggression, defiance, } \\
\text { overactivity, negative emotionality, } \\
\text { anxiety and withdrawal; BITSEA) }\end{array}$ & 1580 & \\
\hline No problems & & $1344(85.06)$ \\
\hline Possible problems & & $236(14.94)$ \\
\hline
\end{tabular}

Among women with mental health risk, $77 \%$ had a history of mental health disorder(s) and $58 \%$ had a history of experiencing abuse. Among women categorised with mental health risk, $20 \%$ had symptoms of depression during pregnancy, $17 \%$ at 4 months postpartum, $21 \%$ at 1 year postpartum and $30 \%$ at 2 years postpartum. The proportion of women categorised with mental health risk with anxiety symptoms during pregnancy, 4 months postpartum, 1 year postpartum and 2 years postpartum was $38 \%, 42 \%, 47 \%$ and $37 \%$, respectively.

Among children with mothers with high maternal mental health risk, $18 \%$ of children had developmental problems. Factors most protective of 'at-risk' development status at age 2 on the ASQ were having a mother with higher social support during pregnancy, and more relationship happiness at 1 year postpartum (table 3 ).

Among children with mothers with high maternal mental health risk, $16 \%$ of children had delayed socialemotional abilities. Factors most protective of socialemotional problems at age 2 on the BITSEA were having a mother who reported more relationship happiness at 1 year postpartum, less difficulty balancing family, work and other responsibilities and the child being exposed to $<1$ hour of screen time per day (table 4 ). 
Table 3 Model of protective factors for overall child development (ASQ) among children with mothers with high maternal mental health risk $(n=266)$

\begin{tabular}{|c|c|c|c|}
\hline Factor & OR & $95 \% \mathrm{Cl}$ & p Value \\
\hline \multicolumn{4}{|c|}{ Social support during pregnancy (MOS-SSS) } \\
\hline Higher (MOS-SSS>69) & 2.56 & 1.29 to 5.09 & 0.007 \\
\hline Lower (MOS-SSS $\leq 69)$ & Ref & & . \\
\hline \multicolumn{4}{|c|}{ Happiness in their relationship at 1 year postpartum } \\
\hline More happiness & 2.76 & 1.31 to 5.81 & 0.008 \\
\hline Less happiness & Ref & & . \\
\hline
\end{tabular}

Table 4 Model of protective factors for social-emotional development (BITSEA) among children with mothers with high maternal mental health risk $(n=289)$

\begin{tabular}{|c|c|c|c|}
\hline Factor & OR & $95 \% \mathrm{Cl}$ & p Value \\
\hline \multicolumn{4}{|l|}{ Happiness in their relationship at 1 year postpartum } \\
\hline More happiness & 2.34 & 1.10 to 5.00 & 0.028 \\
\hline Less happiness & ref & . & . \\
\hline \multicolumn{4}{|c|}{ Mother's perceived ability to fulfil family, work or other responsibilities when child was 2 years old } \\
\hline It is never or sometimes difficult & 2.07 & 1.02 to 4.20 & 0.044 \\
\hline It is difficult most of the time/it is always difficult & ref & . & . \\
\hline \multicolumn{4}{|c|}{ Screen time per day (television, movies/DVDs, computer/tablet) } \\
\hline$>1$ hour & 2.23 & 1.09 to 4.53 & 0.027 \\
\hline 1 hour or more & ref & . & . \\
\hline
\end{tabular}

Among children with mothers with high maternal mental health risk, $24 \%$ of children had behavioural problems. Factors most protective of behaviour problems at age 2 on the BITSEA were having a mother who reported higher optimism during pregnancy, less difficulty balancing family, work and other responsibilities, the child being able to fall asleep in $<30 \mathrm{~min}$ at night and sleeping through the night by age 2 (table 5 ).

Given the importance of SES and certain demographic factors (eg, born in Canada, maternal age) for child development, all final multivariable models were checked for robustness by examining the extent to which SES or demographic variables confounded the associations. None of these variables were significant predictors during final model building and did not confound the associations for any child outcome.

\section{DISCUSSION}

Using a community sample of mothers and children in a major urban centre in Canada, this study described developmental problems at age 2 and identified protective factors for developmental problems in a subgroup of families with maternal mental health risk. Maternal mental health risk was common, affecting $27 \%$ of women in our sample, which is similar to previously reported rates of $25 \% .^{12}$

Poor sleep habits have previously been linked to poor child developmental outcomes including child behaviour problems, ${ }^{30}$ poorer learning capacity and academic performance. $^{31}$ Our findings extend this research by identifying that good sleep habits may act as a protective factor for child social-emotional and behavioural development when mothers are experiencing poor mental health. It is hypothesised that having a child who sleeps well provides mothers, especially those with mental health concerns, with a reprieve from the demands of caring for a young child. Consequently, educating and providing parents with strategies on how to establish healthy sleep habits, including self-settling skills, may be a low cost, effective strategy to reduce the risk of adverse child development outcomes.

The negative consequences of marital dissatisfaction and marital conflict on child development including insecure parent-child attachment, externalising and internalising behaviour problems and social difficulties have previously been reported. ${ }^{32}{ }^{33}$ Our findings add to this research by suggesting that in the presence of poor maternal mental health, relationship happiness may protect children from the negative developmental consequences of poor maternal mental health. Public health well-baby visits and parenting programmes could screen mothers of young children for poor mental health and relationship happiness to assist with identifying families who may benefit from additional supports and wellness strategies. Programmes that are targeted at parents of young children could include content that addresses the stresses of parenting and the value of communication and conflict resolution strategies. 
Table 5 Model of protective factors for behavioural development (BITSEA) among children with mothers with high maternal mental health risk $(n=301)$

\begin{tabular}{|c|c|c|c|}
\hline Factor & OR & $95 \% \mathrm{Cl}$ & p Value \\
\hline \multicolumn{4}{|l|}{ Optimism during pregnancy (LOT-R) } \\
\hline Higher (LOT-R>13) & 2.18 & 1.20 to 3.98 & 0.010 \\
\hline Lower (LOT-R $\leq 13)$ & ref & & . \\
\hline \multicolumn{4}{|c|}{ Mother's perceived ability to fulfil family, work or other responsibilities when child was 2 years old } \\
\hline It is never or sometimes difficult & 2.03 & 1.10 to 3.75 & 0.023 \\
\hline It is difficult most of the time/it is always difficult & Ref & & \\
\hline \multicolumn{4}{|l|}{ Time it takes child to fall asleep at night (in general) } \\
\hline $30 \mathrm{~min}$ or less & 2.17 & 1.10 to 4.27 & 0.026 \\
\hline More than $30 \mathrm{~min}$ & Ref & & . \\
\hline \multicolumn{4}{|l|}{ When child started sleeping through the night } \\
\hline Before 2 years & 2.83 & 1.32 to 6.07 & 0.008 \\
\hline Is not sleeping through the night yet & Ref & & \\
\hline
\end{tabular}

Maternal social support has previously been identified as a protective factor for child development outcomes. ${ }^{21} 34$ Our findings extend the current research by suggesting that, among mothers with poor mental health, establishing a strong social support network as early as possible in pregnancy has ongoing protective effects on children's development up to age 2. Primary care, public health, prenatal and parenting programmes could inform parents about the importance of establishing a social support network, and help parents identify places where support networks can be developed in community and other settings. Indeed, this is supported by a Swedish study that found that participation in childbirth and parenthood education classes in the postpartum period expanded the social network for new mothers. ${ }^{35}$

Optimism was identified as a protective factor for child behavioural development among children cared for by mothers with mental health problems. Optimism is defined as a relatively stable, general tendency of individuals to expect positive outcomes in life. ${ }^{36}$ In this study, maternal optimism was measured during pregnancy, but given the stability of this trait over time, it is likely that mothers reporting higher optimism during pregnancy would continue to report higher optimism in the early parenting years. Optimistic individuals are more likely to adapt to stressors more effectively, ${ }^{37}$ suggesting that optimistic mothers may be better able to adapt to their new role as a parent and the associated challenges of raising a young child. Optimism has also been linked to positive parenting practices. ${ }^{38}$ These findings, linking maternal optimism to improved coping with stress and effective parenting practices, may help to explain how maternal optimism may play a role in children's behavioural development. Although dispositional optimism is a relatively stable trait, research indicates that, to some extent, optimism can be taught, ${ }^{39}$ and therefore early intervention and parenting programmes could include content aimed at cultivating maternal optimism.
Mothers were asked to describe their ability to fulfil family, work or other responsibilities (eg, volunteer work, household duties and other children) since giving birth to their child. Among mothers experiencing poor mental health, those who reported 'it is difficult most of the time' or 'it is difficult all of the time' were more likely to have a child with a social-emotional delay or behaviour problems at age 2 compared with mothers who reported 'it is never or sometimes difficult'. This concept of challenges and conflict among women's life roles has been well documented in the literature. ${ }^{40}$ Challenges with balancing family and work roles is associated with increased rates of depression, stress, anxiety and lower life satisfaction. ${ }^{40}$ Parental stress and poor maternal coping have been found to be associated with child behaviour problems. ${ }^{41}$ Our findings suggest that supporting new parents with strategies to prevent parents from feeling overwhelmed with balancing their roles and responsibilities provides an opportunity to improve early child social-emotional and behavioural development in contexts of poor maternal mental health.

An association between early childhood television exposure and child behaviour problems has previously been reported. ${ }^{42-44}$ Our findings add to the current research by suggesting that limiting all forms of screen time, including television, computers, tablets and smartphones to $<1$ hour per day, may decrease the risk of developmental delay in young children exposed to poor maternal mental health. Since society, including young children, spends more time on tablets, smartphones and computers, it will be important in future research to consider screen time from all types of media, not just television viewing. Limiting all forms of screen time to $<1$ hour per day at age 2 may provide a simple strategy to share with parents of young children to protect against developmental delays.

We further examined protective factors for child development problems among the remaining group of families without identified maternal mental health risk 
(results not shown). Although some protective factors were common to both groups, others were specific to families with mental health risk, which supports the suggestion for targeted interventions. Unique protective factors in high-risk settings included higher social support in pregnancy and relationship happiness in the first postpartum year; these factors were not found to be protective in low-risk settings. Common protective factors, improving mother's coping skills to balance work and family life, enhancing maternal optimism in the early parenting years, limiting children's screen time and establishing good sleep habits, suggest opportunities to apply universal intervention strategies.

A limitation of this study was the use of parent report measures, the ASQ and the BITSEA to operationalise the child development outcomes instead of clinical diagnosis. Therefore, the child development outcomes are based on parents' perceptions of their child's development and the possibility for misclassification must be considered when interpreting the findings of this analysis. For example, children whose parents do not express concerns about their child's development may be delayed, and children whose parents identify concerns may not actually be experiencing clinically relevant developmental problems. However, both the ASQ and BITSEA were selected in this study because of the established reliability and validity, ${ }^{15-17}$ their practical use in a written questionnaire, and their widespread use in clinical and research settings. We further acknowledge that these scales have a generally low positive predictive value (PPV); despite good reliability and validity, scales with low PPVs warrant caution in interpretation, especially in terms of clinical relevance of development and behavioural problems.

We cannot discount the possibility of reporting bias in that some of the protective factors identified might have a different meaning among mothers with mental health risk (eg, optimism, relationship happiness) or reverse causality bias, given that some factors examined occurred at the same time point as our outcomes. As for the child outcomes, all protective factors were selfreported, and a more detailed assessment of important protective factors, such as stimulation and nurturance, was not available, which could also lead to potential misclassification and residual confounding. Finally, given the large number of protective factors examined among the subgroup of families at maternal mental health risk, there is risk for type 1 error, even with the conservative $p$ value of 0.1 that was used in the bivariate analysis.

The sample recruited in this study reflects the sociodemographics of the pregnant and parenting population in Calgary, Canada. ${ }^{14}$ However, these sociodemographics, including the percentage with postsecondary education, higher income and married/common law, may be higher than that observed in other populations, and therefore the generalisability of our findings to other populations should be interpreted with caution. Comparison of $\mathrm{AOB}$ participants at the time of recruitment to provincial and national statistics show that a greater proportion of women in AOB had higher incomes and were married. In addition, there is the potential for selection bias given the attrition and different sample characteristics between participants at recruitment and those remaining at 2 years; those remaining at follow-up in the early years were more likely to have higher SES, to be older, to be in a stable relationship and to be born in Canada.

\section{CONCLUSIONS}

This study further supports previous findings that poor maternal mental health through the perinatal and first two postpartum years is common, affecting more than one in four mothers. We identified key modifiable factors that are protective against developmental delays at age 2 in the presence of poor maternal mental health. Further research and evaluation of interventions that enhance mother's social support, relationship happiness, optimism, and coping with balancing family, work and life roles is warranted. Similarly, identifying evidence informed strategies for supporting parents to optimise children's sleep from infancy to age 2 and educating parents about limiting screen time from all sources in the early years offers opportunities to positively influence early child development. Some potential strategies include engaging public health nurses during well-child clinic visits, which are visits that occur mainly for the purpose of immunisation and other needs including postpartum depression screening and psychosocial assessment in the first postpartum year in Alberta. Further research is warranted to examine protective factors in the presence of severe and chronic maternal mental health problems (ie, trajectories) using more data waves. This work is currently underway.

Acknowledgements The authors acknowledge the contribution and support of $A O B$ team members and our participants. They are extremely grateful to all the families who took part in this study and the whole All Our Babies team. The authors are also extremely grateful to the investigators, coordinators, research assistants, graduate and undergraduate students, volunteers, clerical staff and managers.

Contributors SCT is responsible for the overall integrity, progress, questionnaire development and timely completion of the AOB study. SWM, HLK and SCT were involved in the conception and design of this study. SWM and HLK drafted the manuscript. HLK conducted the data analysis. All authors helped to conceptualise ideas, interpret findings, and review and revise drafts of the manuscript.

Funding This work was supported by Alberta Innovates Health Solutions through Interdisciplinary Team Grant \#200700595 and by providing salary support for SCT. The Alberta Children's Hospital Foundation provided additional funding support for the AOB study for cohort maintenance and follow-up.

\section{Competing interests None declared.}

Ethics approval This study was approved by the Conjoint Health Research Ethics Board at the University of Calgary (Ethics ID 20821 and 22821).

Data sharing statement Requests for data from the All Our Babies Study, and other studies, can be made to the Child Data Centre of Alberta, managed 
by the Alberta Centre for Child, Family and Community Research by emailing data@research4children.com.

Open Access This is an Open Access article distributed in accordance with the Creative Commons Attribution Non Commercial (CC BY-NC 4.0) license, which permits others to distribute, remix, adapt, build upon this work noncommercially, and license their derivative works on different terms, provided the original work is properly cited and the use is non-commercial. See: http:// creativecommons.org/licenses/by-nc/4.0/

\section{REFERENCES}

1. First LR, Palfrey JS. The infant or young child with developmental delay. N Engl J Med 1994;330:478-83.

2. Tough SC, Siever JE, Leew S, et al. Maternal mental health predicts risk of developmental problems at 3 years of age: follow up of a community based trial. BMC Pregnancy Childbirth 2008;8:16.

3. Guevara JP, Gerdes M, Localio R, et al. Effectiveness of developmental screening in an urban setting. Pediatrics 2013;131:30-7.

4. Hertzman C. The state of child development in Canada: are we moving toward, or away from, equity from the start? Paediatr Child Health 2009;14:673-6.

5. Romano E, Babchishin L, Pagani LS, et al. School readiness and later achievement: replication and extension using a nationwide Canadian survey. Dev Psychol 2010;46:995-1007.

6. Gray SAO, Carter AS, Briggs-Gowan MJ, et al. Growth trajectories of early aggression, overactivity, and inattention: relations to second-grade reading. Dev Psychol 2014;50:2255.

7. Briggs-Gowan MJ, Carter AS. Social-emotional screening status in early childhood predicts elementary school outcomes. Pediatrics 2008:121:957-62

8. Campbell SB, Shaw DS, Gilliom M. Early externalizing behavior problems: toddlers and preschoolers at risk for later maladjustment. Dev Psychopathol 2000;12:467-88.

9. Coie JD, Dodge KA, Kupersmidt JB. Peer group behavior and social status. In: Asher SR, Coie JD, eds. Peer rejection in childhood. New York, NY: Cambridge University Press, 1990:17-59.

10. Walden T, Lemerise E, Smith MC. Friendship and popularity in preschool classrooms. Early Educ Dev 1999;10:351-71.

11. Kingston D, Tough S. Prenatal and postnatal maternal mental health and school-age child development: a systematic review. Matern Child Health J 2014;18:1728-41.

12. Kingston $D$, Heaman $M$, Fell $D$, et al. Factors associated with perceived stress and stressful life events in pregnant women findings from the Canadian Maternity Experiences Survey. Matern Child Health J 2012;16:158-68.

13. Walker SP, Wachs TD, Grantham-McGregor S, et al. Inequality in early childhood: risk and protective factors for early child development. Lancet 2011;378:1325-38.

14. McDonald SW, Lyon AW, Benzies KM, et al. The all our babies pregnancy cohort: design, methods, and participant characteristics. BMC Pregnancy Childbirth 2013;13(Suppl 1):S2.

15. Limbos MM, Joyce DP. Comparison of the ASQ and PEDS in screening for developmental delay in children presenting for primary care. J Dev Behav Pediatr 2011;32:499-511.

16. Briggs-Gowan MJ, Carter AS, Irwin JR. The brief infant-toddler social and emotional assessment: screening for social-emotional problems and delays in competence. J Pediatr Psychol 2004;29:143-55.

17. Briggs-Gowan MJ, Carter AS. Brief Infant-Toddler Social and Emotional Assessment (BITSEA) manual, version 2.0. New Haven, CT: Yale University, 2002.

18. Squires J, Bricker D, Potter L. Revision of a parent-completed development screening tool: ages and stages questionnaires. $J$ Pediatr Psychol 1997;22:313-28.

19. Oberklaid F, Efron D. Developmental delay-identification and management. Aust Fam Physician 2005;34:739.

20. Rydz D, Srour M, Oskoui M, et al. Screening for developmental delay in the setting of a community pediatric clinic: a prospective assessment of parent-report questionnaires. Pediatrics 2006;118: e1178-86.
21. Cabaj JL, McDonald SW, Tough SC. Early childhood risk and resilience factors for behavioural and emotional problems in middle childhood. BMC Pediatr 2014;14:166.

22. Cox JL, Holden JM, Sagovsky R. Detection of postnatal depression. Development of the 10-item Edinburgh Postnatal Depression Scale. Br J Psychiatry 1987;150:782-6.

23. Radloff LS. The CES-D scale: a self-report depression scale for research in the general population. Appl Psychol Meas 1977;1:385-401.

24. Spielberger CD, Gorsuch RL, Lushene R, et al. Manual for the state-trait anxiety inventory. Palo Alto, CA: Consulting Psychologists Press, 1983.

25. Tough SC, Siever JE, Benzies K, et al. Maternal well-being and its association to risk of developmental problems in children at school entry. BMC Pediatr 2010;10:19.

26. Sherbourne CD, Stewart AL. The MOS social support survey. Soc Sci Med 1991;32:705-14

27. Scheier MF, Carver CS, Bridges MW. Distinguishing optimism from neuroticism (and trait anxiety, self-mastery, and self-esteem): a reevaluation of the Life Orientation Test. J Pers Soc Psychol 1994:67:1063-78

28. Trute B, Hiebert-Murphy D. Predicting family adjustment and parenting stress in childhood disability services using brief assessment tools. J Intellect Dev Disabil 2005;30:217-25.

29. Statistics Canada. NLSCY Cycle 5-User Guide. Section 9.5.8 Social Support Scale. 2002-2003. http://www23.statcan.gc.ca/ imdb-bmdi/document/4450_D4_T9_V5-eng.pdf (accessed Feb 2016).

30. Lam P, Hiscock H, Wake M. Outcomes of infant sleep problems: a longitudinal study of sleep, behavior, and maternal well-being. Pediatrics 2003;111:e203-7.

31. Dewald JF, Meijer AM, Oort FJ, et al. The influence of sleep quality, sleep duration and sleepiness on school performance in children and adolescents: a meta-analytic review. Sleep Med Rev 2010;14:179-89.

32. Howes P, Markman HJ. Marital quality and child functioning: a longitudinal investigation. Child Dev 1989;60:1044-51.

33. Katz LF, Gottman JM. Patterns of marital conflict predict children's internalizing and externalizing behaviors. Dev Psychol 1993;29:940.

34. Huang CY, Costeines J, Ayala C, et al. Parenting stress, social support, and depression for ethnic minority adolescent mothers: impact on child development. J Child Fam Stud 2014;23:255-62.

35. Fabian HM, Rådestad IJ, Waldenström U. Childbirth and parenthood education classes in Sweden. Women's opinion and possible outcomes. Acta Obstet Gynecol Scand 2005;84:436-43.

36. Scheier MF, Carver CS. Optimism, coping, and health: assessment and implications of generalized outcome expectancies. Health Psychol 1985;4:219-47.

37. Scheier MF, Weintraub JK, Carver CS. Coping with stress: divergent strategies of optimists and pessimists. J Pers Soc Psychol 1986;51:1257-64

38. Taylor ZE, Larsen-Rife D, Conger RD, et al. Life stress, maternal optimism, and adolescent competence in single mother, African American families. J Fam Psychol 2010;24:468-77.

39. Seligman M. Positive psychology, positive prevention, and positive therapy. In: Snyder CR, Lopez SJ, eds. Handbook of positive psychology. New York, NY: Oxford University Press, 2002:3-9.

40. Amstad FT, Meier LL, Fasel U, et al. A meta-analysis of workfamily conflict and various outcomes with a special emphasis on cross-domain versus matching-domain relations. J Occup Health Psychol 2011;16:151.

41. Crnic KA, Gaze C, Hoffman C. Cumulative parenting stress across the preschool period: relations to maternal parenting and child behaviour at age 5. Infant Child Dev 2005;14:117-32.

42. Christakis DA, Zimmerman FJ, DiGiuseppe DL, et al. Early television exposure and subsequent attentional problems in children. Pediatrics 2004;113:708-13.

43. Mistry KB, Minkovitz CS, Strobino DM, et al. Children's television exposure and behavioral and social outcomes at 5.5 years: does timing of exposure matter? Pediatrics 2007;120:762-9.

44. Cheng S, Maeda T, Yoichi S, et al. Early television exposure and children's behavioral and social outcomes at age 30 months. J Epidemiol 2010;20(Suppl 2):S482-9. 